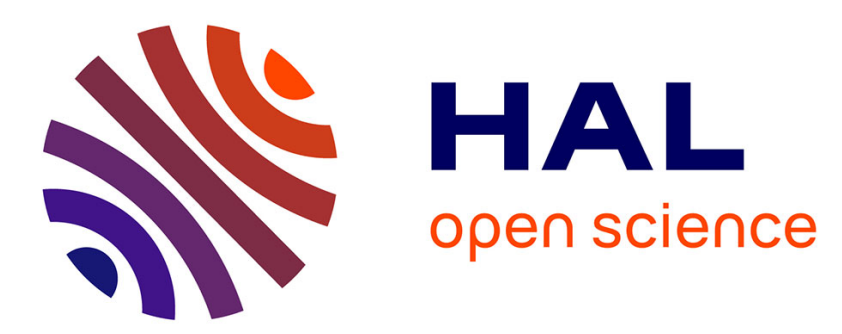

\title{
Non-uniform distribution of small-scale inhomogeneities in melt-spun Fe80B20 ribbons
}

\author{
R. Kranold, G. Walter, M. Stubicar
}

\section{To cite this version:}

R. Kranold, G. Walter, M. Stubicar. Non-uniform distribution of small-scale inhomogeneities in melt-spun Fe80B20 ribbons. Journal de Physique IV Proceedings, 1993, 03 (C8), pp.C8-333-C8-336. 10.1051/jp4:1993867 . jpa-00252298

\section{HAL Id: jpa-00252298 https://hal.science/jpa-00252298}

Submitted on 1 Jan 1993

HAL is a multi-disciplinary open access archive for the deposit and dissemination of scientific research documents, whether they are published or not. The documents may come from teaching and research institutions in France or abroad, or from public or private research centers.
L'archive ouverte pluridisciplinaire HAL, est destinée au dépôt et à la diffusion de documents scientifiques de niveau recherche, publiés ou non, émanant des établissements d'enseignement et de recherche français ou étrangers, des laboratoires publics ou privés. 


\title{
Non-uniform distribution of small-scale inhomogeneities in melt-spun $\mathrm{Fe}_{80} \mathrm{~B}_{20}$ ribbons
}

\author{
R. KRANOLD, G. WALTER and M. STUBIČAR* \\ Fachbereich Physik, Abt. Materialwissenschaft und Strukturforschung, Universität Rostock, \\ 18051 Rostock, Germany \\ * Department of Physics, University of Zagreb, P.O. Box 162, 41001 Zagreb, Croatia
}

\begin{abstract}
Amorphous melt-spun $\mathrm{Fe}_{80} \mathrm{~B}_{20}$ ribbons have been investigated by small-angle $\mathrm{X}$ ray scattering to extract additional information on small-scale inhomogeneities observed in transition metal-metalloid glasses by several authors. Our experiments have shown that the scattering heterogeneities of electron density, the dimensions of which amount to about $1 \mathrm{~nm}$, exist only in regions adjacent to the edges of the ribbons studied. This emergence suggests that the scattering items cannot be identified with intrinsic features of the amorphous state of the $\mathrm{Fe}_{80} \mathrm{~B}_{20}$ alloy. There are several reasons to assume that the scattering heterogeneities are attributable to devitrification processes running down in the regions adjacent to the edges of the ribbons where possibly the quenching velocity is reduced.
\end{abstract}

\section{Introduction}

In the last decade several authors [1-3] observed inhomogeneities on a very small size scale of about 1 $\mathrm{nm}$ in transition metal-metalloid (T-M) glasses by the aid of small-angle neutron (SANS) or X-ray (SAXS) scattering. In order to discuss the observed scattering effects, most of the authors used quasicrystalline or two-phase models corresponding to existing structure models, which have been constructed to explain the known experimental facts concerning the short-range order in T-M glasses. On the other hand, the results of small-angle scattering experiments have been used to motivate the development of refined models of the atomic medium-range order in these glasses [1, 4]. Consequently, it seems to be very important to check carefully whether the small-scale heterogeneities observed in T-M glasses by SANS and SAXS are intrinsic features of the amorphous state of these materials or not. In this paper we present the results of SAXS studies performed on amorphous meltspun $\mathrm{Fe}_{80} \mathrm{~B}_{20}$ ribbons.

\section{Experimental}

Ribbons of $35 \mu \mathrm{m}$ thickness and $2 \mathrm{~mm}$ width having the nominal chemical composition $\mathrm{Fe}_{80} \mathrm{~B}_{20}$ were prepared using the melt-spinning device described in [5]. The SAXS measurements were performed using a Kratky camera with Mo radiation and a Rigaku Denki low-angle goniometer with Mo or Ag 
radiation, respectively. To convert the observed power into electron units (eu), a calibrated Lupolen standard sample was used. Further details of the experiment and data treatment are given in [6].

\section{$\underline{\text { 3. Results }}$}

Fig. 1 shows SAXS curves recorded with the Kratky camera from the $\mathrm{Fe}_{80} \mathrm{~B}_{20}$ ribbon in two different orientations in respect to the primary beam cross section. At very small values of the scattering vector, in the range $s<1 \mathrm{~nm}^{-1}$, both scattering curves exhibit a power-law scattering, which is a unique feature of the small-angle scattering curves of metallic glasses [1]. This scattering effect is caused by fluctuations at large scales. Due to the slit collimation system of the Kratky camera, the exponent of the power-law scattering was obtained to be -2 rather than -3 that would be observed by using a point collimation system. SANS experiments performed on metallic glasses [1] yielded exponents in the range between -3 and -4 .

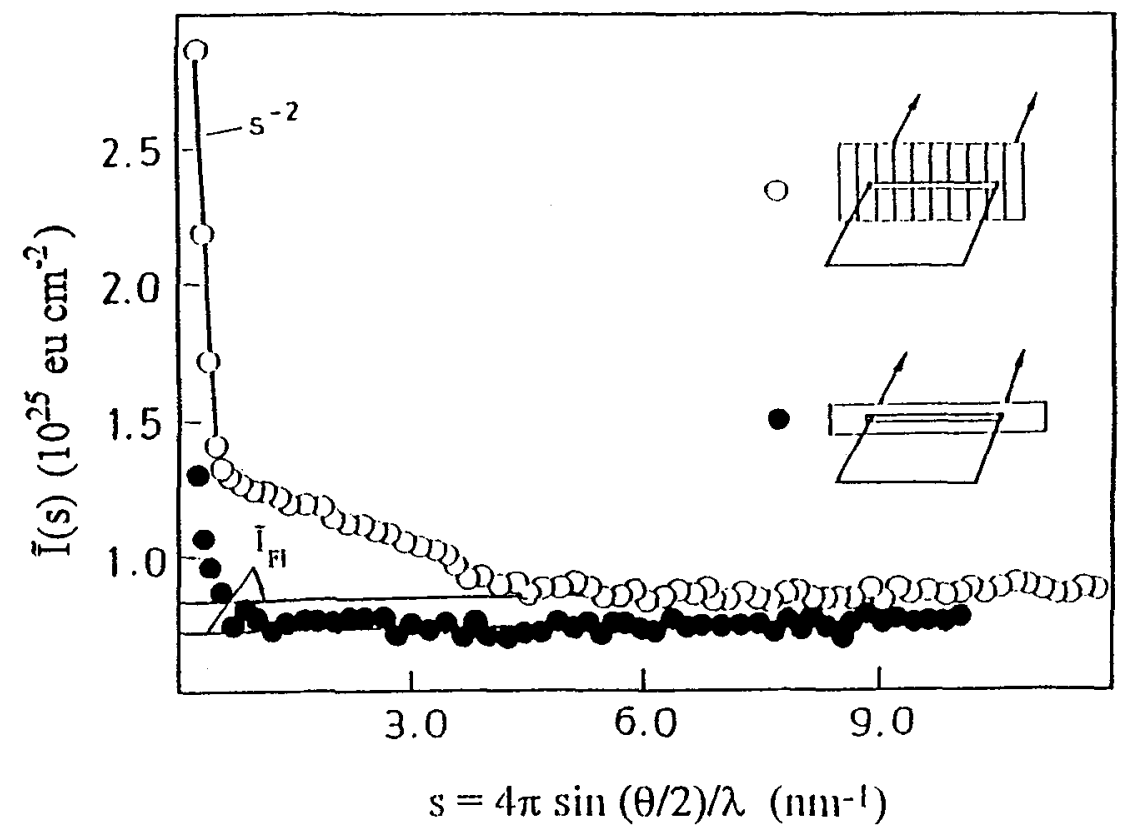

Fig. 1 SAXS curves of $\mathrm{Fe}_{80} \mathrm{~B}_{20}$ ribbons measured by the Kratky camera. In the right hand side of the plot, the orientation of the ribbon in respect to the primary beam cross section is demonstrated.

In the upper curve of Fig. 1, where the entire ribbon in the direction of the width was penetrated by the primary beam, as done by SANS experiments, a second scattering effect can be observed for $s>1 \mathrm{~nm}^{-1}$ resulting from small-scale inhomogeneities of electron density, $\rho$. The radius of gyration of the inhomogeneities determined by the aid of a Guinier plot (Fig. 2, curve b) is $R_{G}=0.3 \mathrm{~nm}$. From the integrated intensity the mean square electron density fluctuations were determined to be $\overline{(\Delta \rho)^{2}}=2.8 \times 10^{45}(\mathrm{eu})^{2} \mathrm{~cm}^{-6}$. (The scattering of frozen-in thermodynamic fluctuations, $\tilde{\mathrm{I}}_{\mathrm{Fl}}$, of concentration and/or density was substracted before computing the integral intensity.) 
Provided that the scattering system consists of two phases formed by $\mathrm{Fe}_{3} \mathrm{~B}$ and $\alpha-\mathrm{Fe}$, the magnitude of the mean square electron density fluctuations can be calculated according to $\overline{(\Delta \rho)_{\text {calc }}^{2}}=\mathrm{w}(1-\mathrm{w})(\Delta \rho)^{2}=5 \times 10^{45}(\mathrm{eu})^{2} \mathrm{~cm}^{-6}$ where $\mathrm{w}=0.2$ is the volume fraction of $\alpha-\mathrm{Fe}$ and $\rho=2.207 \times 10^{24} \mathrm{eu} \mathrm{cm}^{-3}$ and $\rho=2.036 \times 10^{24} \mathrm{eu} \mathrm{cm}^{-3}$ are the electron densities [3] of $\alpha-\mathrm{Fe}$ and $\mathrm{Fe}_{3} \mathrm{~B}$, respectively. Basically, the $\overline{(\Delta \rho)^{2}}$ value obtained experimentally has the same order of magnitude as the calculated value which represents a maximum for a two-phase system, but further quantitative discussions would require the assumption of refined models.

Surprisingly, the scattering effect caused by the small-scale inhomogeneities cannot be detected if the primary beam strikes only the regions near to the ribbon axis (lower curve in Fig. 1 and curve a in Fig. 2). This result was verified using the Rigaku Denki goniometer with different kinds of radiation (Fig. 2, curves $\mathrm{c}, \mathrm{d}, \mathrm{e}, \mathrm{f}$ ). Doubtless, small deviations in the determined $R_{\mathrm{G}}$ values result from differences in the smearing conditions, since different collimation systems and radiations were used.

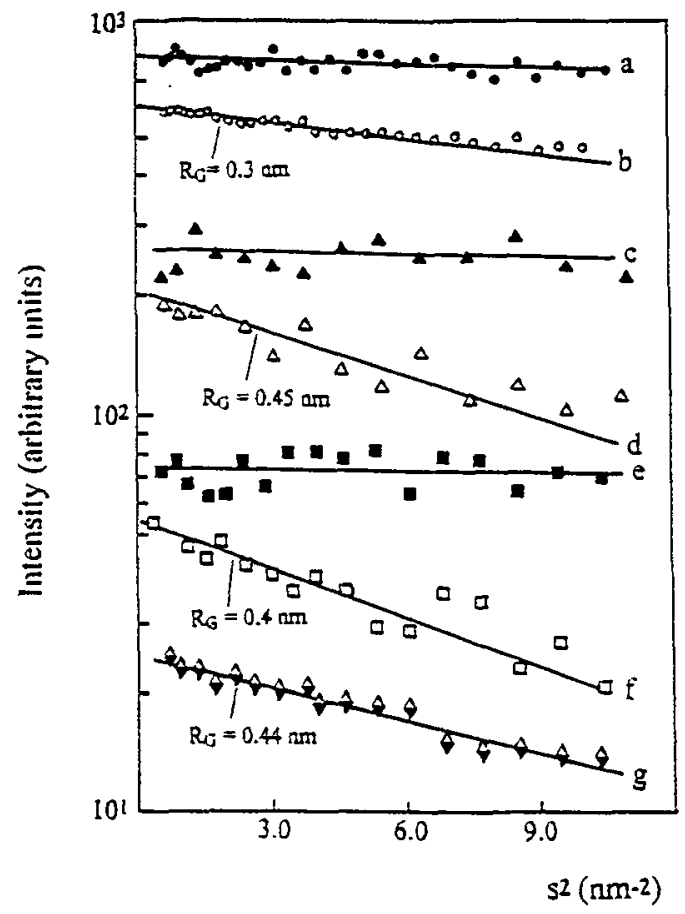

Fig. 2 Guinier plot of SAXS curves obtained from $F e_{80} B_{20}$ ribbons $\left(0.4 \leq s R_{G} \leq 1.5\right)$.

The ribbons were oriented in respect to the primary beam cross section as follows:

a, $\mathrm{c}, \mathrm{e}$ - only the middle part of the ribbon was penetrated

$b, d, f$ - the entire ribbon in the direction of the width was penetrated

g- the orientation was that choosen for $a, c, e$ but the region adjacent to the edge was exposed to radiation.

Curves a, b were measured with the Kratky camera and Mo radiation, $\mathrm{c}$ and $\mathrm{d}$ with the Rigaku denki goniometer using $\mathrm{Ag}$ radiation, and $\mathrm{e}, \mathrm{f}, \mathrm{g}$ with the latter device but Mo radiation. 
The assumption that the small-scale inhomogeneities discussed above are located in regions of the ribbon adjacent to the edges only was confirmed by a scattering experiment where the orientation of the ribbon axis was chosen to be parallel to the length of the primary beam cross section, but in contrast to the experiments $a, c$ and $e$, the region adjacent to the edge was exposed to radiation. The result of this experiment is shown in Fig. 2, curve $g$.

\section{Discussion}

The presence of small-scale inhomogeneities of about $1 \mathrm{~nm}$ in size was established in the $\mathrm{Fe}_{80} \mathrm{~B}_{20}$ ribbons studied. However, the inhomogeneities are not distributed uniformly across the material, but they are located in regions adjacent to the edges of the ribbon only.

These findings suggest that the small-scale inhomogeneities frequently observed in quenched T-M glasses by small-angle scattering techniques do not represent intrinsic features of the amorphous state of these materials, but they are devitrification phenomena introduced by imperfect quenching conditions. The latter conclusion is supported by Pavuna's [7] results, which show that a curvature of the bottom surface, which contacted the roller, and two "ridges" at both edges of the upper ribbon surface very often exist at melt-spun ribbons. These imperfections may cause that the quenching velocity is reduced near the edges.

\section{References}

[1] Lamparter P., Steeb S., J. Non-Cryst. Solids 106 (1988) 137

[2] Feigel G., Svab E., in: Rapidly Quenched Metals V, Vol. 1, p. 487

(North-Holland, Amsterdam, 1985)

[3] Osamura K., Shibue K., Suzuki R., Murakami Y., Takayama S., J. Mater. Sci. 16 (1981) 957

[4] Hermann H., Mattern N., J. Phys. F: Met. Phys. 16 (1986) 131

[5] Liebermann H. H., Graham Jun. C. D., IEEE Trans. Magn. MAG-12 (1976) 921

[6] Walter G., Kranold R., Göcke W., Enenkel N., J. Appl. Cryst. 24 (1991) 616

[7] Pavuna D., J. Non-Cryst. Solids 37 (1980) 133 